\title{
Large Groin Mass due to Vascular Transformation of Lymph Node Sinuses
}

\author{
Avinash Dal \\ Department of Cardiothoracic and Vascular Surgery, Virinchi Hospitals, Hyderabad Telangana India.
}

\section{Corresponding Author:}

Dr Avinash Dal

Email: bestcardiacsurgery@gmail.com

This is an Open Access article distributed under the terms of the Creative Commons Attribution License (creativecommons.org/ licenses/by/3.0).

Received Accepted

Published

July 28, 2019

December 30, 2019

January 25, 2020

\begin{abstract}
Background: Vascular transformation of lymph node sinuses is a relatively rare entity and usually seen in the cervical lymph nodes. Case Report: A seventeen year old young male came with a progressively growing, painless swelling in the right groin. The mass was firm and had transmitted pulsations from the femoral vessels. As it was in close proximity to the femoral vessels, it was referred for excision. Histopathology and immunohistochemistry demonstrated true angiogenesis. Conclusion: The case is presented noting the combination that pathology is rare and its presentation in groin lymph nodes is rarer.
\end{abstract}

Keywords: Immunohistochemistry, Lymphadenopathy, Lymphatic Vessels, Lymph nodes, Neck.

\section{Introduction}

Vascular transformation of lymph node sinuses is a rare entity and is found to affect the lymph nodes in the neck more than anywhere else. Most of the reports quote only few numbers of cases and that too usually in the neck. The exact pathogenesis of this disorder is not described in literature. There are typically no predisposing factors. It is not clear as to whether the enlargement of nodes is a response to non-specific lymphadenopathy or due to a specific infective insult.

\section{Case Report}

A seventeen year old male presented with a large painless right groin swelling measuring about $7 \mathrm{~cm}$ in diameter growing progressively over a period of 3 months. The mass was not painful and there were no systemic (fever, malaise, anorexia, etc.) or local symptoms (pain, rise in local temperature or redness of skin). There was no history of any predisposing conditions such as fever, local trauma, skin infection/pathology. Further examination failed to reveal any other masses other than this primary site. The mass was a single, firm, nontender, free from skin and with restricted mobility over the underlying neurovascular structures. There were transmitted pulsations palpable in the mass but it was neither expansile nor compressible. Trans-illumination test was negative.

Two attempts of fine needle aspiration cytology (FNAC) were attempted and both times, only blood cells were seen without any abnormal cytology. Ultrasonography of abdomen and chest reontgenography were normal. Ultrasonography demonstrated a solid homogenous mass with no active Doppler signals. Arterial and venous Doppler scan of the right leg demonstrated no abnormality within the right femoral artery or vein. The complete blood count was normal. In view of these findings, the patient underwent an excision biopsy. The exact diagnosis could not be pinpointed in view of the clinical and ultrasound findings.

Intra-operatively, the mass was not attached to the skin and was partially adherent to the femoral sheath [Fig.1]. It was well encapsulated and the surface was not inflamed. There were no 
inflammatory adhesions surrounding the mass. The mass was excised totally with the capsule intact. No other nodes or masses were palpable in the surrounding area. A corrugated plastic drain was placed as the cavity left behind after excision of the mass was large and the wound was closed in layers with Polyglactin 2-0 and skin was closed with 3-0 Polyglactin subcuticular sutures.

Histopathological studies [Fig.2] revealed small, dilated vessels, which were lined by a single layer of endothelial cells and with scattered areas of solid spindle proliferation without mitotic figures. There were some zones of fibrosis and plasma cell infiltrates along with hemosiderin laden macrophage proliferation. Extravasation of red blood cells in between the few preserved lymphoid follicles was also seen. There were mature blood vessels in the subcapsular area. Immunohistochemistry demonstrated focal positivity in the plump ovoid to spindle cells for cluster of differentiation marker (CD31). SMA (small muscle actin marker) and cluster of differentiation marker (CD 34) were absent. This suggested true angiogenesis and not any other tissue.

The patient had an uneventful recovery barring the fact that he developed a wound seroma requiring aspiration and compression dressing for a week.

\section{Discussion}

Vascular transformation of lymph node sinuses is a rare condition that is reported in literature albeit sporadically. Most of the lesions were reported in the lymph nodes of the head and neck region [1,2] and almost never in the groin. Occasionally, myoid [3] and nodular transformation of these lesions are described, perhaps due to the fact that stem cells are ubiquitously present. In certain cases, the node transforms into a sponge like structure consisting only of vascular sinusoids. The amount of spindle cell proliferation may also vary [4]. Malignancy is excluded by the lack of mitotic figures.

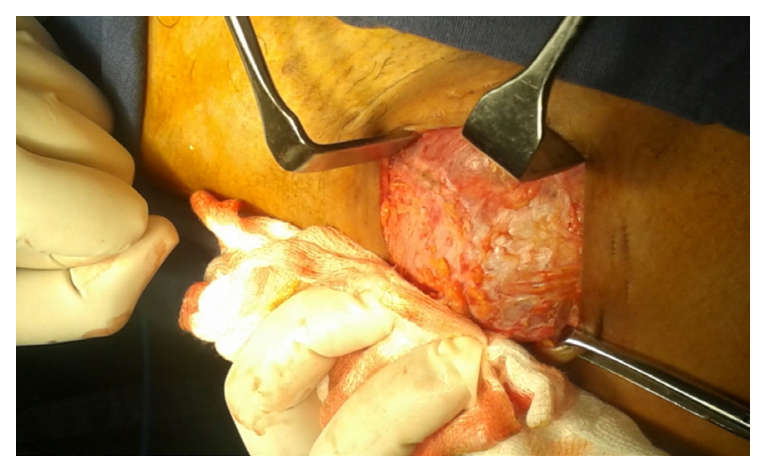

Fig.1: Surgical exposure of the groin mass.

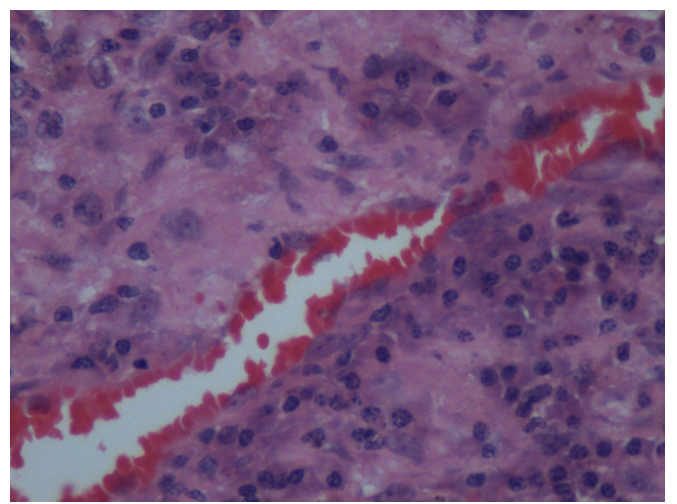

Fig.2: Histology of the mass: large vascular sinuses are seen running through midst of lymphoid tissue. There are red corpuscles seen in the sinuses.

The pathology usually does not affect more than a single nodal group or regions outside of the primary site. The pathology also does not metastasize. Nodal hemangiomatosis present similarly to the vascular transformation of sinuses with the difference that the transformation may occur in the hilum of the node or the medullary areas, as histologically, the vascular tissue is present in that area [5]. Vascular transformation of the lymph node sinuses occurs in non-malignant lesions that do not result in any metastases nor do they cause local invasion. Treatment usually is excision. It is theorized that these lesions result from the obstruction of efferent and venous pathways extending from the lymph nodes $[6,7]$.

The author thus presents this case of a firm, non-tender slow growing, and clinically 
undiagnosable groin mass which upon histological examination was determined to be a rare case of vascular transformation of lymph node. In this patient, the atypical region was in the groin unlike the usual cervical region as reported in literature. It is a benign treatable condition. The case is presented noting the combination that pathology is rare and its presentation in groin lymph nodes is rarer.

\section{Conclusion}

Vascular transformation of lymph node sinuses in the groin appeared as a painless, unprovoked mass and is a rare variant of an unusual pathology.

Contributors: AD did manuscript editing, patient management and will act as a study guarantor. He is responsible for the final version of this manuscript and all aspects of the study.

Funding: None; Competing interests: None stated.

\section{References}

1. Samet A, Gilbey P, Talmon Y, Cohen H. Vascular transformation of lymphnode sinuses. J Laryng Otol. 2001;115:760-762.
2. Ghosh P, Saha K Ghosh AK. Vascular transformation of bilateral cervical lymph nodes: a rare entity masquerading as tumour recurrence. Jour Maxilofac Oral Surg. 2015;14:397-400.

3. Michal M, Koza V, Fakan F. Myoid differentiation in vascular transformation of lymph node sinuses due to venous obstruction. Immunohistochemical and ultrastructural studies. Zentralbl Pathol. 1992;138:2733.

4. Jindal B, Vashishta RK, Bhasin DK. Vascular transformation of sinuses in lymphnodes associated with myelodysplastic syndrome - a case report. Indian Journal Pathol Microbiol. 2001;44:453-455.

5. Elgoweini M, Chetty R. Primay nodal hemangioma. Arch Path Lab Med. 2012;136:110-112.

6. Haferkamp O, Rosenau W, Lenner K. Vascular transformation in lymph node due to venous obstruction. Arch Pathol. 1971;92:81-83.

7. Chan JKC, Warnke RA, Dorfman R. Vascular transformation of sinuses in lymphnodes, a study of its morphological spectrum and distinction from Kaposis sarcoma. Am J Surg Pathol. 1991;15:732-743. 